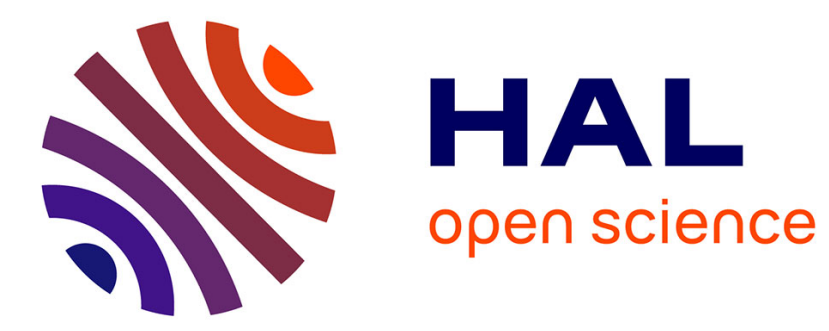

\title{
New trends in creep microstructural models for pure metals
}

\author{
Daniel Caillard, J.L. Martin
}

\section{To cite this version:}

Daniel Caillard, J.L. Martin. New trends in creep microstructural models for pure metals. Revue de

Physique Appliquée, 1987, 22 (3), pp.169-183. 10.1051/rphysap:01987002203016900 . jpa-00245528

\section{HAL Id: jpa-00245528 \\ https://hal.science/jpa-00245528}

Submitted on 1 Jan 1987

HAL is a multi-disciplinary open access archive for the deposit and dissemination of scientific research documents, whether they are published or not. The documents may come from teaching and research institutions in France or abroad, or from public or private research centers.
L'archive ouverte pluridisciplinaire HAL, est destinée au dépôt et à la diffusion de documents scientifiques de niveau recherche, publiés ou non, émanant des établissements d'enseignement et de recherche français ou étrangers, des laboratoires publics ou privés. 


\title{
REVUE DE PHYSIQUE APPLIQUÉE
}

Revue Phys. Appl. 22 (1987) 169-183

MARS 1987, PAGE 169

\author{
Classification
}

Physics Abstracts

$62.20 \mathrm{H}$

\section{New trends in creep microstructural models for pure metals}

\author{
D. Caillard $\left(^{*}\right)$ and J. L. Martin $\left({ }^{* *}\right)$ \\ (*) Laboratoire d'Optique Electronique du CNRS, BP 4347, F-31055 Toulouse Cedex, France. \\ (**) DP Ecole Polytechnique Fédérale, CH1015 Lausanne, Switzerland.
}

(Reçu le 17 septembre 1986, révisé le 20 novembre, accepté le 25 novembre 1986)

\begin{abstract}
Résumé. - Divers modèles microstructuraux décrivant les mécanismes qui gouvernent la vitesse de déformation en fluage sont discutés. Ils sont examinés par comparaison avec les données microscopiques et macroscopiques relatives aux structures et propriétés des sous-joints et sous-grains et aux distributions de contraintes internes. Il est montré que pour identifier un mécanisme réaliste, il faut tenir compte non seulement des paramètres d'activation mais aussi des observations métallographiques. Des résultats récents sur le glissement dévié montrent que ce mécanisme pourrait contrôler la vitesse de déformation en fluage dans le cuivre aux températures intermédiaires, tandis que dans le même domaine de température, le glissement prismatique est actif dans le magnésium. Pour l'aluminium, la migration des sous-points joue un rôle important aux températures intermédiaires et elle est gouvernée par le glissement de dislocations des sous-joints dans des plans (001). Le glissement sur des plans non compacts dans les sous-grains contrôle la vitesse de déformation en fluage pour ce métal à la limite inférieure du domaine des hautes températures. Le modèle de traînage des crans sur les dislocations vis apparaît particulièrement irréaliste. Des observations supplémentaires sur le glissement dévié et sur le glissement dans des plans non compacts sont nécessaires afin de pouvoir généraliser ce type de modèle à d'autres métaux.
\end{abstract}

\begin{abstract}
Various microstructural rate controlling models of creep are reviewed. They are compared to macroscopic and microscopic data for subgrain, subboundary structures and properties, and internal stress distributions. It is shown that the identification of realistic mechanisms not only requires the examination of activation parameters values, but also necessitates relevant metallographic observations. Recent data on cross slip show that this mechanism could control the creep rate of copper at intermediate temperatures while glide on prismatic planes is active in magnesium in a similar temperature range. For aluminium, subboundary migration plays an important role at intermediate temperatures, and is controlled by the glide of subboundary dislocations on (001). Glide on non compact planes inside subgrains controls the creep rate in this metal at the onset of the high temperature domain. The jog dragging screw model is particularly unrealistic. Additional data on cross slip and glide on non compact planes are needed to generalize the above models to other metals.
\end{abstract}

\section{Introduction.}

The aim of this paper is to concentrate on various microstructural mechanisms which have been proposed to control the creep rate in the case of substructure forming materials. This list of mechanisms is not exhaustive. Only the most recent ones, or these frequently quoted, will be critically examined. Earlier models can be found in excellent previous reviews [1-4].

A complete description of the creep process is not available at the moment, since the role of the substructure is certainly not well understood. Questions such as which internal stresses should be considered in the constitutive equations, or how mobile dislocations interact with the substructure, are not fully answered. Nevertheless we will review recent data related to different deformation mechanisms. These include direct observations of dislocation motion in the electron microscope, observations of dislocation arrangements which were pinned under load and also constant strain rate tests and load relaxation experiments. Attention will be focussed on the stress and temperature sensitivity of the strain rate, i.e. the activation parameter values which have been measured corresponding to dislocation mechanisms such as cross slip and glide on non compact planes in the FCC and the HCP structures. These parameters will be compared to those 
measured in creep to distinguish realistic and unrealistic creep models.

The significant temperature and stress ranges corresponding to sets of coherent values of activation parameters will be first recalled. Most of the time, constitutive equations corresponding to stage II of creep (constant strain rate) will be considered. Then, the main microstructural features observed and the associated internal stress fields will be described in connection to dislocation mobility under such conditions. The interactions of mobile dislocations with the subboundaries will be examined in terms of the geometrical features of the latter. Attention will then be focussed on subboundary migration : how the mechanism operates and how it is connected to the build up of internal stresses. Various interpretations of the power law regime and its breakdown will be reviewed next. Then the main rate controlling mechanisms which have been postulated will be exposed, with a critical examination of the role of cross slip and glide on non compact planes.

\section{Temperature and stress domains.}

The creep rate is a function of various parameters including stress and temperature. Numerous data are available on the strain rate dependence of these two variables in stage II of creep. The temperature dependence is characterized by an experimentally determined activation energy. Several authors consider that this parameter tends to exhibit rather constant values within given temperature ranges as summarized in figure 1 .

A high temperature domain can be defined for which the activation energy is traditionally assumed to be equal to that for self diffusion. Likewise, an " intermediate temperature " range with a lower activation energy can be defined, as well as a « ultrahigh temperature » domain in HCP metals (see Fig. 1).

Attempts have been made to define the limits of these temperature regimes and at what fraction of the melting point the boundaries of the above domains are situated [8]. If one considers figure 1c, it appears that the transition between the intermediate and high temperature domains is different for different metals. It seems to be higher for smaller stacking fault energies (compare $\mathrm{Cu}$ and $\mathrm{Al}$ for instance). These transition temperatures should also be stress dependent though data on this point are rather scarce.

However, a review by Poirier [9] shows that the situation is not so clear. Activation energies are measured on Arrhenius plots ( $\log \dot{\varepsilon}$ as a function of $1 / T$ for a given $\sigma$ ) and these are not always rectilinear in the different temperature domains quoted above. As a rule it is possible to define a domain where the activation energy is close to that
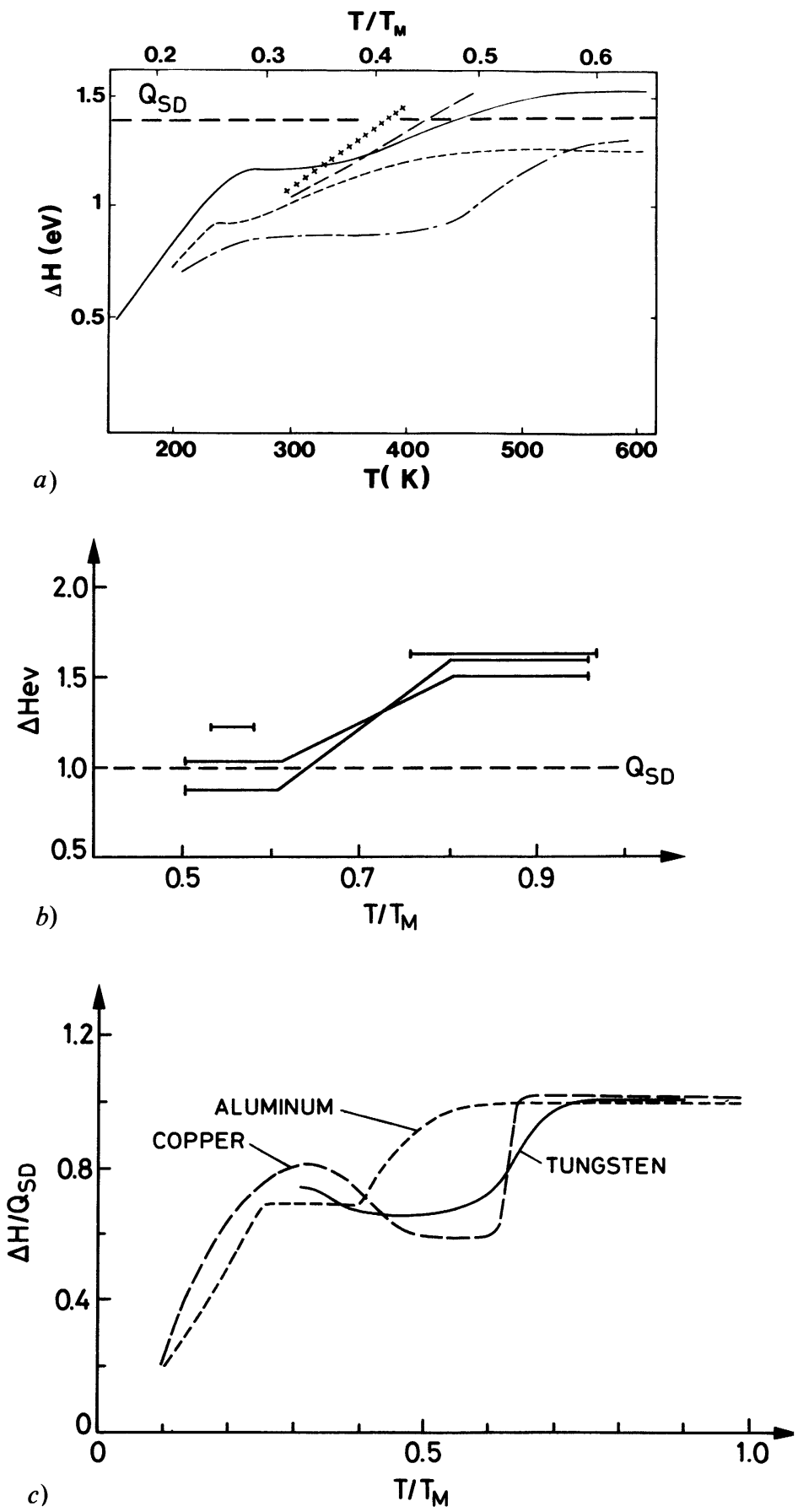

Fig. 1. - Activation enthalpies for stage II of creep as a function of temperature. a) Aluminium. Data from 4 different sources (quoted by [5]) ; b) zinc. Data from 4 different studies (quoted by [6]). $Q_{\mathrm{SD}}=$ self-diffusion energy, $T_{\mathrm{M}}=$ melting point. c) Idealized schematic representation. From [7].

for self diffusion, but it can also be larger at very high temperature (in silver for instance). It can decrease more or less monotonically with decreasing temperature. According to Mecking [10], the intermediate temperature plateau of figure $1 \mathrm{c}$ in $\mathrm{Al}$ could also be an artefact bound to some change in the entropy term. 
If the stress dependence of the strain rate is considered, experimentalists usually measure the stress exponent $n$ which is defined as :

$$
n=\partial \log \dot{\varepsilon} /\left.\partial \log \sigma\right|_{T} .
$$

Values of $n$ for different metals have been reviewed by Blum and Reppich for instance [11]. As an example, typical $n$ values for aluminium can be seen in figure 2 as a function of stress, for a variety of temperatures. At very low creep stresses, i.e. near the melting point, $n$ is close to 1 , and this stress range is usually attributed to Harper-Dorn creep [13]. As the stress increases, $n$ approaches a value of 5 , independent of temperature and stress, and the creep rate appears to obey a power law. The activation energy is therefore constant. For still lower temperatures and higher stresses, $n$ increases with stress and becomes stress and temperature dependent («power law breakdown»).

As an example, the various temperature ranges corresponding to different $n$ values in Aluminium are, according to [11] :

$$
\begin{aligned}
& 0.2 T_{\mathrm{m}}<T<0.55 T_{\mathrm{m}} \Rightarrow n>5 \text {, for any stress } \\
& 0.55 T_{\mathrm{m}}<T<0.8 T_{\mathrm{m}} \Rightarrow n>5 \text {, for high stresses } \\
& n=5 \text {, for low stresses } \\
& 0.8 T_{\mathrm{m}}<T \quad \Rightarrow n=5 \text {, independent of }
\end{aligned}
$$

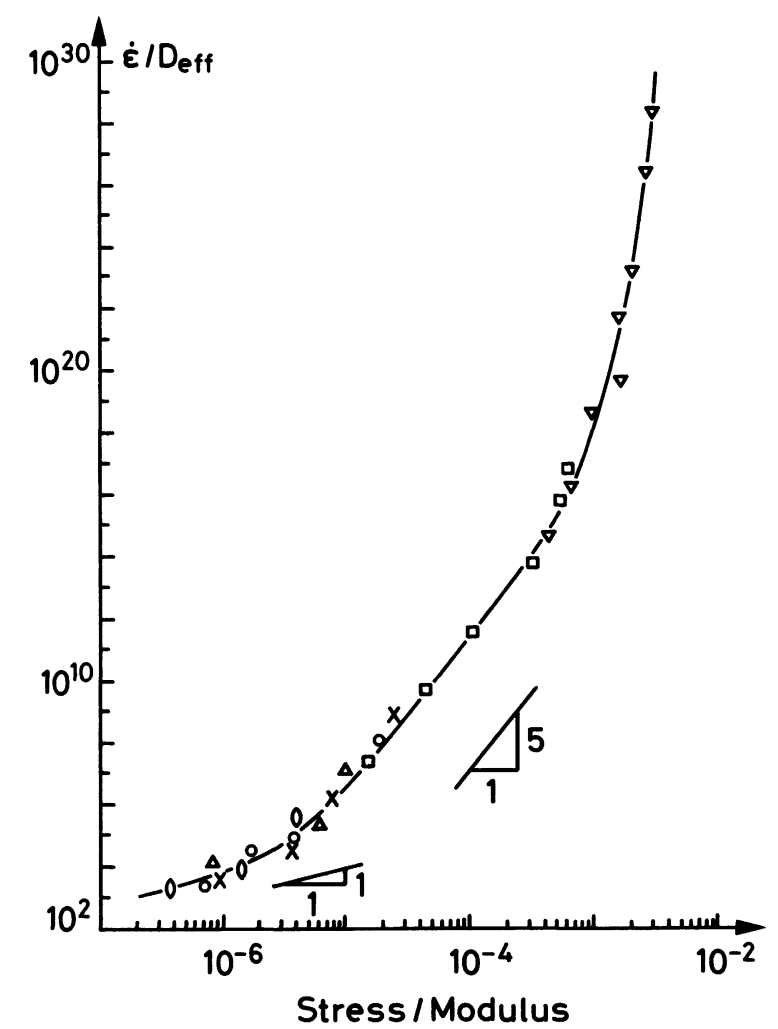

Fig. 2. - Stress dependence of the creep rate for pure aluminium [12]. $D_{\text {eff }}$ refers to an effective diffusion coefficient according to [12]. (From 6 different studies.)

REVUE DE PHYSIQUE APPLIQUÉE. - T. 22, N• 3, MARS 1987
(The Harper Dorn creep range is ignored in this study.)

As the power law breaks down, it is more appropriate to express the strain rate in terms of an activation area, the activation energy becoming stress dependent.

Indeed an activation area can be deduced from experimental data by the relationship :

$$
A=(k T / b)(\partial \log \dot{\varepsilon} / \partial \sigma)_{T}
$$

Then $n$ and $A$ values are correlated by :

$$
n=\sigma A b / k T \text {. }
$$

This correlation is illustrated in figure 3 [11] : an extensive analysis of creep data for 12 different studies in aluminium shows that $n$ is a linear function of the variable $\sigma / T$. Thus as stress increases, or temperature decreases, $n$ values increase, and a constant activation area can be deduced.

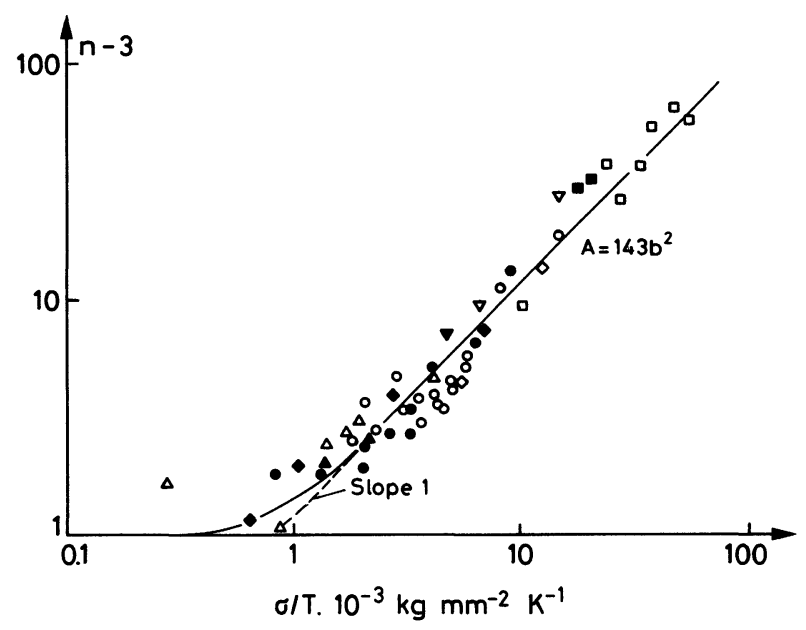

Fig. 3. - Stress exponant $n$ for aluminium as a function of $\sigma / T$. Temperatures between $25^{\circ} \mathrm{C}$ and $647^{\circ} \mathrm{C}$. Evidence of a constant activation area A. From 12 different studies. Quoted in [11].

The description of these various temperature and stress ranges is a bit cumbersome, but in the field of creep there have been no attempts at scaling equivalent to the Ashby maps for constant strain rate tests. In addition, the correlation between constant strain rate and creep tests is not always very obvious. As an example, in aluminium, the transition temperature between two distinct deformation modes (glide on $\{111\}$ or on $\{001\}$ ) has been observed to occur at $180^{\circ} \mathrm{C}$ in creep and $290^{\circ} \mathrm{C}$ at constant strain rate for comparable stresses and strain rates $[14,15]$.

The definition of the above stress and temperature domains is however important with respect to the mechanisms described below. In this paper, we will consider that : 
- the « high temperature » domain is defined by $\Delta G$ (free activation energy for creep) close to $\Delta G_{\mathrm{SD}}$ (self diffusion energy) ( $n$ close to 5 , at least in FCC metals),

- the "intermediate temperature » domain is defined by $\Delta G$ smaller than $\Delta G_{\mathrm{SD}}$ ( $n$ larger than 5 , at least in FCC metals),

- the "ultra high temperature " domain is defined by $\Delta G$ larger than $\Delta G_{\mathrm{SD}}$ (in the case of HCP metals, semiconductors, and some FCC metals).

The experimental data, the microstructural features and the models that will be presented attempt to explain power law behaviour, power law breakdown and the different values of activation areas and energies quoted above. The dislocation substructure which develops and the associated internal stresses will be considered first.

\section{Substructure heterogeneity and internal stresses.}

2.1 SUBSTRUCTURE CHARACTERISTICS. - In the materials considered here, a substructure is built up during deformation which consists of either cells surrounded by dislocation walls, or subgrains and subboundaries. As deformation proceeds in these materials, cells develop and they eventually evolve towards subgrains as dislocations in the walls annihilate and rearrange by short distance climb. This occurs for instance during stage II of creep, or at the end of stage III in constant strain rate tests, provided one or several of the following conditions are fulfilled : a sufficiently high temperature, a high stacking fault energy and/or a large strain.

At least in the case of subgrains, it has been shown that the substructure consists of encased structures of different sizes which may not be revealed by the same technique. Etch pits for instance, reveal structures of a larger size than electron microscopy. For this reason, it is important to keep in mind that the substructure evidenced by a given technique may not be the most significant with regard to the creep rate. In particular, in aluminium $[14,15]$ and in BCC metals, large subgrains which are relatively highly misoriented contain smaller ones with lower misorientations. According to Carrard [15] and Caillard [16], only the smaller subgrains should play an important role during creep of aluminium at intermediate temperatures.

2.2 INTERNAL STRESS DISTRIBUTION. - A consequence of dislocation clustering is that, as the dislocation substructure becomes heterogeneous, the internal stress distribution also becomes heterogeneous. Hard and soft regions within the substructure must be considered. The former regions correspond to high dislocation densities and associated internal stresses such as walls and subboundaries, and the latter to low densities and weak internal stresses such as cell or subgrain interiors.
2.2.1 Experimental evidence. - Such a distribution of stresses has been checked experimentally in the following way. Local stresses in a crystal can be estimated from the radius of curvature of the dislocations measured by TEM (Transmission Electron Microscopy). Reliable measurements can be performed only if the dislocations are pinned at the end of the deformation test, the sample being still under load. A few different pinning techniques have been used depending on the type of mechanical test. In fatigued copper single crystals [17], the dislocations were pinned by neutron irradiation. Dislocations bowing out under stress could be evidenced in the wall structure of the persistant slip bands. Local stresses were found to be as large as about three times the peak stress in the walls and as low as one third of the peak stress in the centre of the channels [17].

In a creep study, precipitation induced by quenching and subsequent aging, has been used to freeze the substructure under load in a $\mathrm{AlZn}$ alloy [18]. Figure 4 shows an example of bowed dislocations at

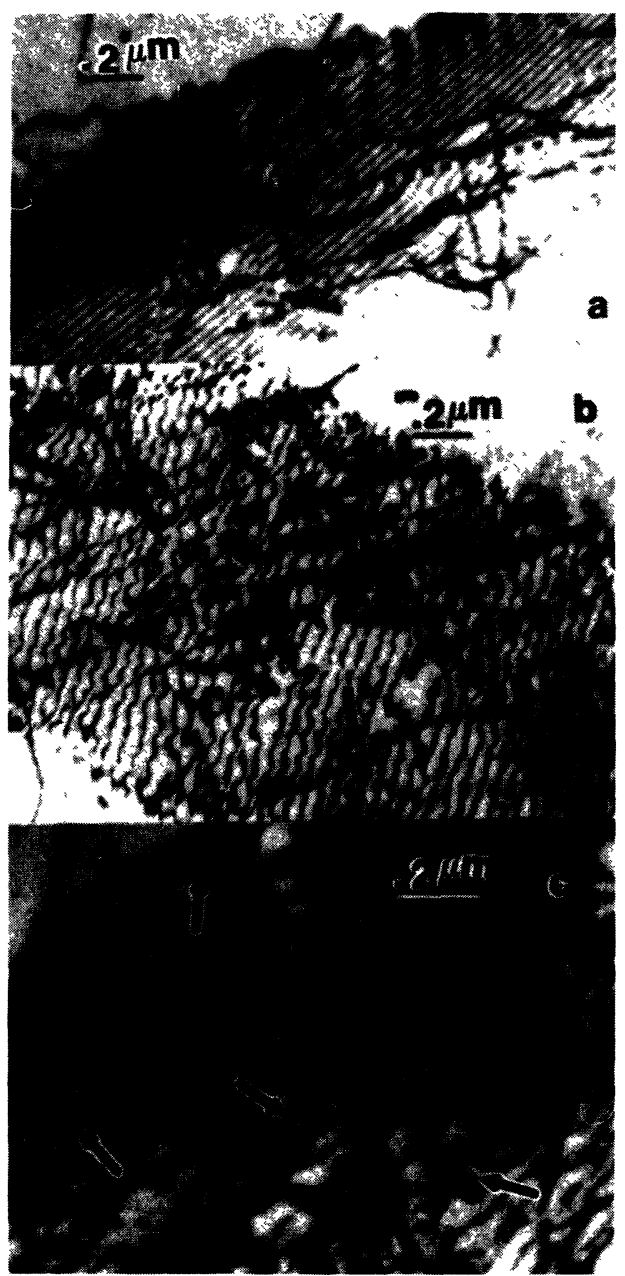

Fig. 4. - Pinned dislocation arrangements in Al-11 wt \% $\mathrm{Zn}$ showing dislocation bowing out of subboundaries. Creep test at $250^{\circ} \mathrm{C}, 8 \mathrm{MPa}$. a) $7 \%$ strain ; b) $10 \%$ strain : c) $15 \%$ strain. From [18a]. 
subboundaries. Such a strong dislocation bowing out of subboundaries has also been observed in in situ creep experiments [19]. At some areas of the subboundaries, the local stress is found to be ten times the applied stress. The stress concentration factor depends on the creep conditions. In figure 5 the variation of the measured local stress as a function of the distance from the boundary has been plotted. However, fatigue walls and creep subboundaries exhibit drastic differences in the distibution of internal stresses. In the latter, the points of highest local stresses are more heterogeneously distributed along the boundary surface.

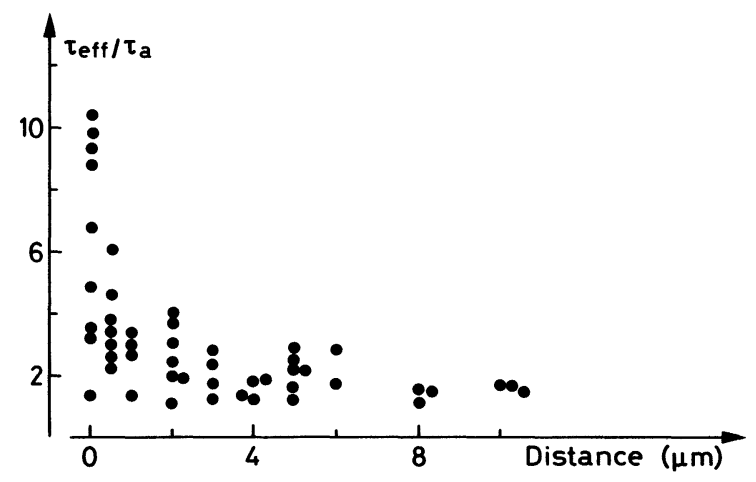

Fig. 5. - Effective shear stresses in units $\tau_{\mathrm{a}}$ as a function from the distance of the subboundary. Al-11 wt \% $\mathrm{Zn}$. Creep test at $250^{\circ} \mathrm{C}, 2.4 \mathrm{MPa}$. Stage II, $7 \%$ strain. From [18a].

2.2.2 Theoretical interpretation. - Estimations based on different assumptions show that local stresses have to be as high as 5 to 10 times the applied stress at creep subboundaries in aluminium $[5,20,21]$.

Two different kinds of interpretation have been proposed :

i) Nix and Ilschner [3], Blum [20, 21], in the case of creep subboundaries, and Mughrabi [17] for fatigue walls, consider the deformed material as a composite, the two phases of which consist of the hard and soft regions which have been described above. Both zones have to be penetrated by moving dislocations (see experimental evidence in \$ 2.3), and the compatibility conditions impose that the local stress $\sigma$ is larger than the applied stress $\sigma_{\mathrm{a}}$ in the hard zones, and lower in the soft ones.

ii) On the other hand, Kocks considers that the hard zones, which are statistically distributed through the crystal, are not connected and undeformable, but rather that dislocations can bow around them [22]. These islands are continuously surrounded by piled up Orowan loops and are therefore under higher stress levels than the applied stress. Dislocation motion through the hard zones is only possible at high stresses with the help of temperature
(Stage III of the stress strain curve for instance). The number of loops thus decreases in such a recovery process. Although the model seems to be attractive for wall or subboundary nucleation at random points in the crystal, the picture of piled up loops does not hold in the case of a subgrain structure in which all subboundaries are interconnected. The continuity of the subboundaries in three dimensions has been confirmed in HVEM (High Voltage Electron Microscope) observations of thick foils [5].

In these two descriptions by Kocks and Mughrabi, interface dislocations (see Fig. 6 [17]) are necessary to accommodate the difference between the elastic and plastic shear strains in the hard and soft zones, respectively. However, because of unavoidable annihilation processes between mobile and interface dislocations this description encounters difficulties in explaining how dislocations cut through the hard zones (see $\S 2.3$ below).

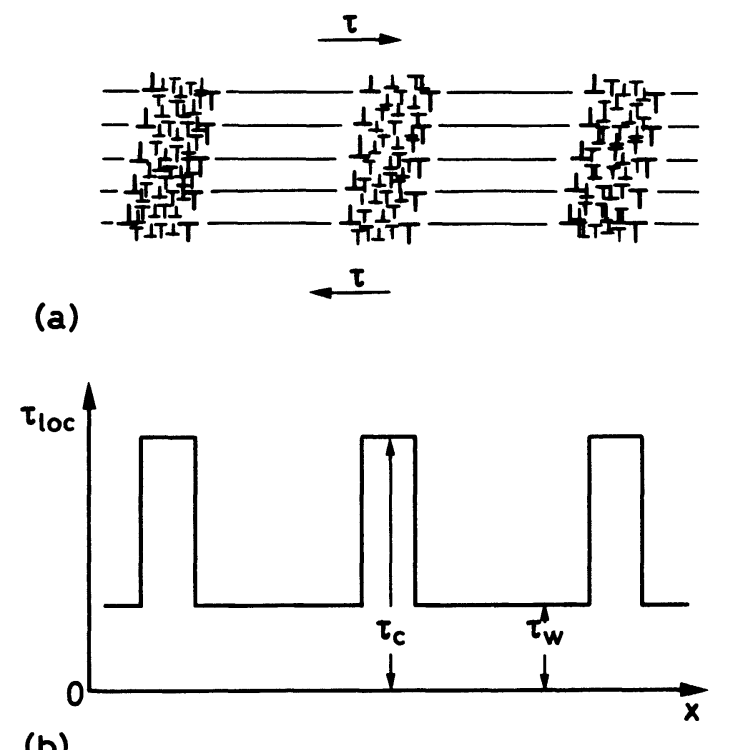

(b)

Fig. 6. - Composite model for the building up of heterogeneous internal stresses in a cell or channel structure (from [17]). a) Scheme of dislocation clustering. b) Local stress distribution in walls $\tau_{w}$ and cell interiors $\tau_{\mathrm{c}}$.

The origin of internal stresses is more difficult to determine for subboundaries. Indeed, in comparison to cell walls, the subboundaries are extremely thin and should be relaxed because they form at relatively high temperatures and in materials with relatively high stacking fault energy. Even under dynamic circumstances, when mobile dislocations react with the subboundaries, thus distorting them locally, short distance climb or cross slip is fast and should erase the local internal stresses (see $\S 4$ below). Various types of models have been proposed :

- subboundaries are not at equilibrium [23] under creep conditions. This should induce high stres- 
ses of positive or negative sign throughout the crystal. However, this model is not energetically reasonable. It also disagrees with numerous analyses of subboundary dislocations which show that, as a rule, the Frank criterion is fulfilled.

- under creep conditions, a flexing of the subboundaries occurs, which also generates internal stresses through the crystal [24]. A two dimensional numerical model has been proposed [25] to visualize the related stress field. Long range internal stresses are developed, with a period of the order of the subgrain size. Nevertheless such a process of subboundary flexing does not account for the cutting of dislocations through subboundaries. In addition insitu experiments [26] have shown that subboundaries migrate, and that the amount of bulging under stress is low since the triple junctions joining adjacent boundaries are also mobile (see $\$ 4$ below).

- A final reason proposed more recently [16] is that high local stresses in the subboundaries are due to a side motion of extrinsic dislocations during migration. The stresses generated at a given subboundary are alternately positive or negative as a function of time. In such a mechanism the high local values of the internal stresses are maintained in spite of the fast climb induced recovery. These ideas will be developed in $\S 4$ below.

2.3 MOBILE DISLOCATIONS AND SUBSTRUCTURE. - In the deformation of such heterogeneous substructures, many different experiments show that in all cases dislocations move over distances larger than the cell or subgrain size, and thus pass through cell walls or subboundaries. This is evidenced by the following results :

- In aluminium creep tested at $300{ }^{\circ} \mathrm{C}$, the slip line length is longer on the average than the subgrain size in stage II [27].

- In situ experiments in copper single crystals, predeformed up to the onset of stage II and thus containing a cell structure of a few $\mu \mathrm{m}$ in average diameter, also show that dislocations cut through most of the dislocation tangles at $20^{\circ} \mathrm{C}$ [28].

Some experimental observations are also available on the cutting through process.

- In aluminium deformed at $20^{\circ} \mathrm{C}$, thin foils have been made near the surface so that the slip traces as well as the dislocation walls could be observed simultaneously in TEM [29]. Slip bands are observed to go across the walls. Although at first sight they seem to cut straight through, a close inspection of the micrographs shows that the number of slip planes in the band is different on both sides. In addition, the larger the strain, the finer and shorter the slip bands.

- In situ experiments between 20 and $200^{\circ} \mathrm{C}$, in precept aluminium samples, have furnished direct evidence of the cutting through process of subboun- daries by mobile dislocations [5] [29-30] (Fig. 7). The detailed geometry of the mechanism has been analysed, yielding clear evidence for cross slip. This latter phenomenon has been confirmed by slip trace analysis by scanning electron microscopy in an aluminium-zinc polycrystal. After a creep strain of $5 \%$ at $250{ }^{\circ} \mathrm{C}$ under a $8 \mathrm{MPa}$ stress, slip was observed to cut through the subboundaries, and sometimes a thick slip trace on one side of the boundary degenerated into several thinner ones on the other side [31]. Such a process of slip line splitting (see an example in Fig. 7) can be interpreted as follows. In coarse slip, typical of stage $I$ in this

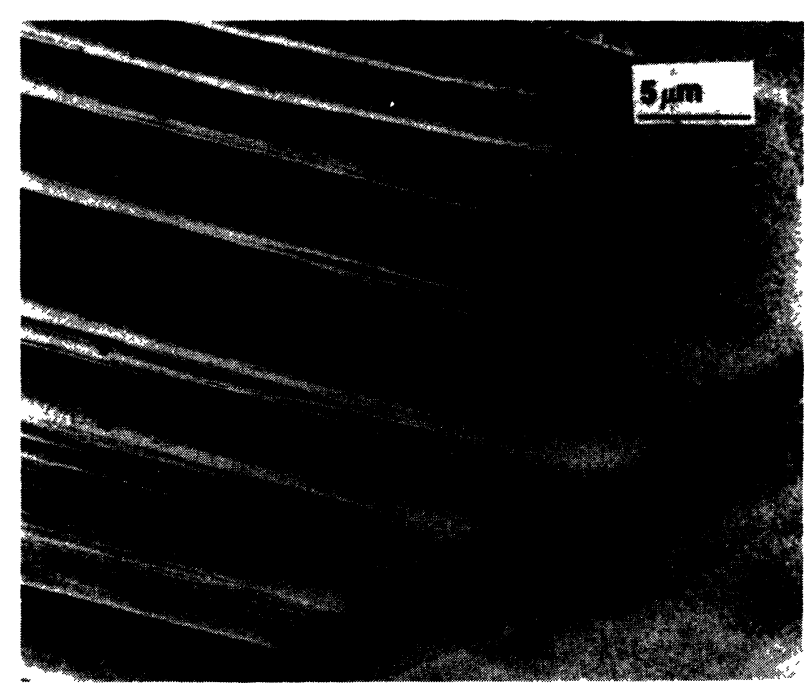

a)

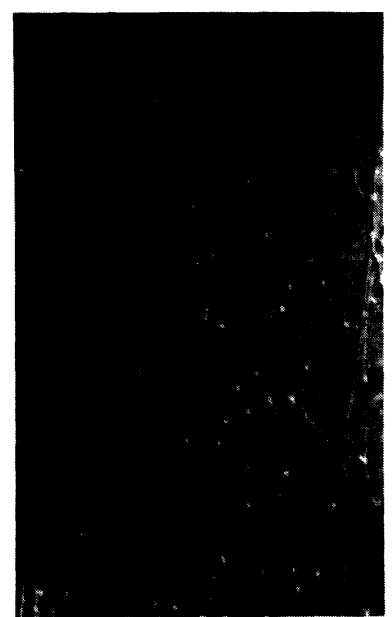

b)

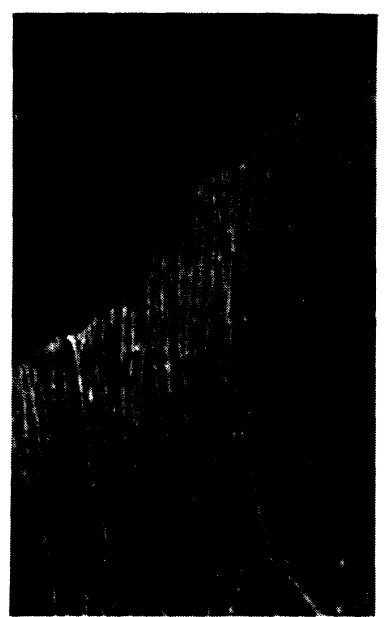

c)
Fig. 7. - Dislocation glide through subboundaries in creep. a) Sharp slip traces degenerate into finer ones, presumably at subboundaries near a grain boundary. Al11 wt \% $\mathrm{Zn}$ creep tested at $200^{\circ} \mathrm{C}, 7 \mathrm{MPa}, 5 \%$ strain. Scảnning electron microscope. From [31]. b) and c) Sequence of an in situ creep experiment in $\mathrm{Al}$ at $250^{\circ} \mathrm{C}$ showing that many dislocations (see traces) have been gliding through a subboundary (from [32]). 
alloy, dislocation groups encounter a subboundary and emerge on the other side on a different slip plane because of the cross slip process. Thus, heterogeneous glide transforms into fine slip at the end of stage I. In stage II where subboundaries are present all through the grains, only fine slip is observed [31].

It therefore seems clearly established that the mean free path of the dislocations is larger than the cell size. The mechanism of penetration is not a trivial one and has not been fully understood.

Since the interaction of mobile dislocations and subboundaries seems to be an important event during stage II of creep, attention will be focussed now on the subboundaries.

\section{Subboundary structure and knitting.}

3.1 GeOMETRICAL FeAtURes. - A detailed analysis of the subboundary geometry requires the determination of the boundary plane and the Burgers vectors directions and densities of the dislocation families involved as well as the misorientation. Then, if the Frank criterion is satisfied, the network is a real subboundary (no or only weak long range stresses), and is a configuration of minimum energy.

In $\mathrm{Al}$, subboundaries consist mostly of two independant dislocation families at intermediate temperatures [33]. At higher temperatures more families are present (five in the case of AlZn 11 wt \% alloy at $\left.250{ }^{\circ} \mathrm{C}[18]\right)$, and the density of extrinsic dislocations is lower. At intermediate temperatures, subboundaries satisfy the Frank criterion, and generally the long range stresses are less than or equal to the applied stress $\sigma_{\mathrm{a}}$ [33]. Some cases of « out of equilibrium " subboundaries which have been described in [23] have long range stresses that are within the upper limit of the applied stress. Subboundaries are of many different geometries, and can be classified as follows :

- pure tilt (one family of parallel dislocations),

- pure twist (square network in $\{100\}$ planes, and hexagonal networks in $\{111\}$ planes),

\section{- mixed.}

Most subboundaries are of mixed character. They appear similar to the hexagonal network, but lie in non crystallographic planes (see for example in Fig. 8).

Finally, although in aluminium subboundaries are formed by climb, dislocations dissociate at the intersection of the subboundary plane and the glide planes because of energetic reasons. One consequence of this is that subboundaries are glissile at intermediate temperatures $(\$ 4)$.

In silicon and germanium, subboundary observations have been done recently by Brion and Haasen after deformation in the so called stages IV and V of the stress strain curve [34]. The authors report

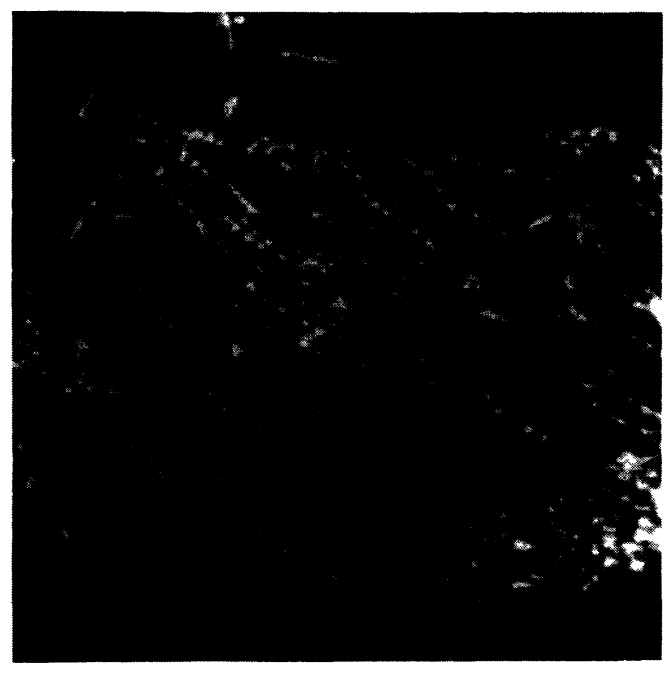

a)

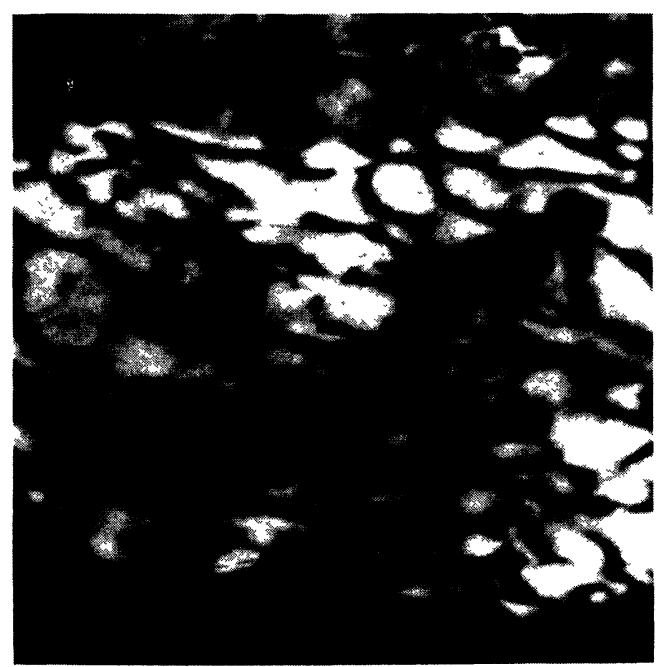

b)

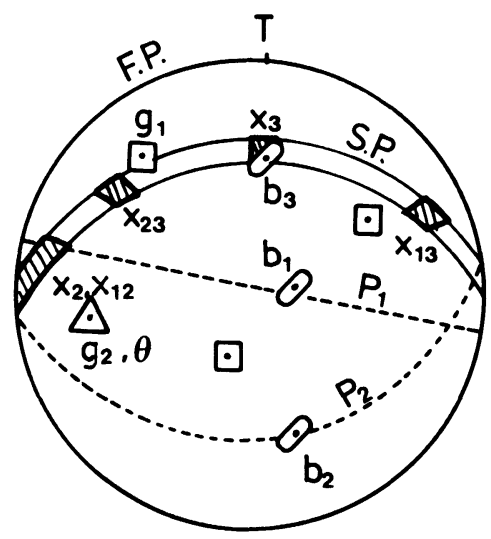

c)

Fig. 8. - Creep subboundary of mixed character. $x_{i}, b_{i}, P_{i}$ : dislocation direction, Burgers vector and glide plane respectively ( $i=1$ to 3 ). Al creep tested at $150{ }^{\circ} \mathrm{C}$. a) Weak beam image at $100 \mathrm{kV}$. b) Subboundary dislocations out of contrast. Extrinsic ones are visible. c) Stereographic projection : FP foil plane. SP subboundary plane. $x_{i j}$ are characteristic directions on a). From [33]. 
networks consisting of three sets of parallel $60^{\circ}$ dislocations (Fig. 9a). These are supposed to react further by climb and then form pure twist hexagonal networks. However, the observed configurations are typical of repulsive dislocations (Fig. 9b), as has been previously observed [35]. Therefore, the process described by the authors is obviously impossible. On the contrary, the network in question is certainly close to a pure tilt subboundary and cannot evolve so easily towards a pure twist one. This shows that the detailed description of a subboundary involves a complete geometrical analysis of the dislocations. In particular there is no obvious correlation between the respective densities of edges and screws in subboundaries, and the relative frequencies of climb and cross slip events, since all dislocations are geometrically necessary.

a)

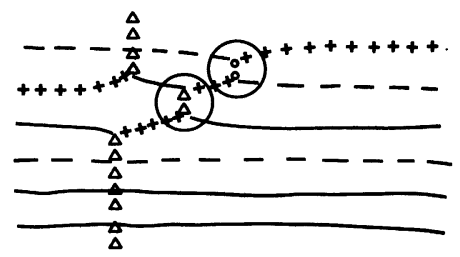

b)

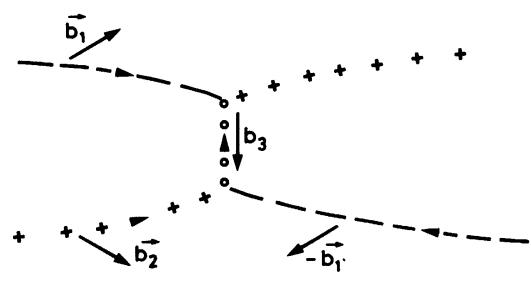

Fig. 9. - Sketch of subboundaries observed in Ge. a) as described in [34]. b) Typical configuration of repulsive dislocations in a subboundary as observed by [35]. (Enlarged view of circled regions in a).)

3.2 SUBBOUNDARY IMPERFECTIONS AND THE KNITTING PROCESS. - In addition to imperfections due to extrinsic dislocations, subboundaries also contain distortions characteristic of their interaction with individual mobile dislocations which usually have the same Burgers vector as subboundary dislocations. These have been observed statically by Myshlyaev in molybdenum and tungsten rapidly cooled after creep [36], in BCC iron alloys by Lindroos et al. [37], and in aluminium deformed in situ using weak beam conditions [30] (see Fig. 10).

These distortions on intrinsic dislocations are very similar in all these materials. Some correspond to the insertion of dislocations inside subboundaries. However, others are interpreted as the result of either dislocation extraction from subboundaries [36] (see an example in Fig. 10) or dislocation insertion followed by annihilation in subboundaries [37]. In

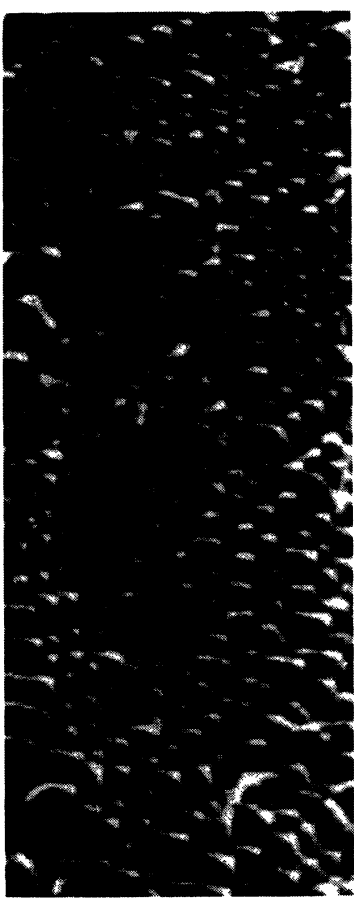

a)

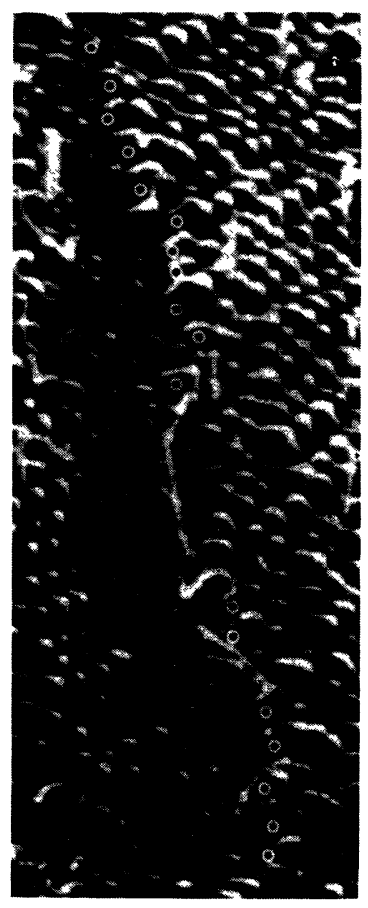

b)

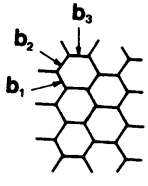

c)

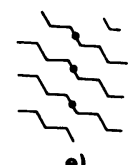

e)
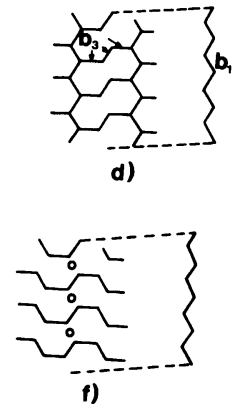

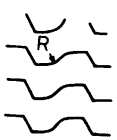

g)
Fig. 10. - Sequence of dislocation extraction from a subboundary consisting of 3 dislocation families. In situ experiment $100 \mathrm{kV}, 20^{\circ} \mathrm{C}$. a) b) Weak beam pictures before and after extraction (10 min. of time interval). Open circles in b) correspond to dots in a). c) and d) Sketch of the process. e) f) as in c) and d) with dislocations of Burgers vector $b_{2}$ out of contrast. e) Corresponds to a). g) as in f) after some recovery by climb (as in b)). From [30].

situ experiments show that these distortions result from both processes, since the interaction between individual dislocations and subboundaries is well described by the knitting model. Indeed, this model accounts for the interaction between mobile dislocations and subboundaries, according to the scheme of figure 11a, unlike interaction models based on infinitely long dislocation (Fig. 11b). Then extraction and annihilation processes are not different $[5,30,39]$.

In situ experiments show that knitting in and knitting out require only glide and cross slip in aluminium at intermediate temperatures $[5,30]$. 

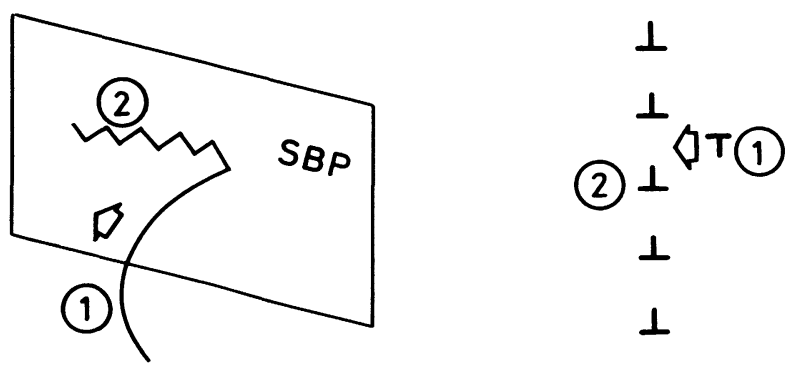

a)

b)

Fig. 11. - Dynamic recovery at a subboundary. a) Cross slip : sketch of an in situ observed mechanism (from [5]). b) Climb of infinitely long dislocations (Weertman model [38]).

Subsequently, the resulting distortions are recovered by climb which maintains the regularity of the subboundary structure during creep. This occurs at a speed of $10^{-2} \AA / \mathrm{s}$ at $20^{\circ} \mathrm{C}$ in aluminium [30], and probably much faster at higher temperatures $[37,40]$, (e.g. 2000 times faster at $\left.200{ }^{\circ} \mathrm{C}[19]\right)$. This explains why distortions can only be observed after rapid cooling, dislocation pinning, or dynamically during in situ experiments.

Two important consequences are :

1) Distortion recovery is too rapid to control creep. The amount of recovery necessary to maintain a quasi stationnary stage of creep is achieved by the knitting mechanism itself as explained by Blum $[39,40]$.

2) Distortion recovery is too rapid to satisfactorily explain the presence of high local internal stresses inside subboundaries, so that it is necessary to take into account the migration process.

We will now discuss subboundary migration and describe this mechanism in detail.

\section{Subboundary migration.}

A review of the first observations of subboundary migration during creep and high temperature deformation can be found in [26] (see for example in Fig. 12). Recent observations confirm that this phenomenon occurs in many different materials. These results are reported below, including the measured strain due to migration $\left(\varepsilon_{\mathrm{SB}}\right)$ as compared to the total strain $\varepsilon_{\mathrm{T}}$.

It is also mentioned in [42] and [44] that in LiF and $\mathrm{NaCl}$, the velocity of subboundaries decreases as their misorientations increase.

It appears then that subboundary migration is a general feature of creep, since it occurs in very different materials, for a wide range of temperatures and, most strikingly, with a more or less constant contribution to the total strain (around $10 \%$ on average, except for [41]).

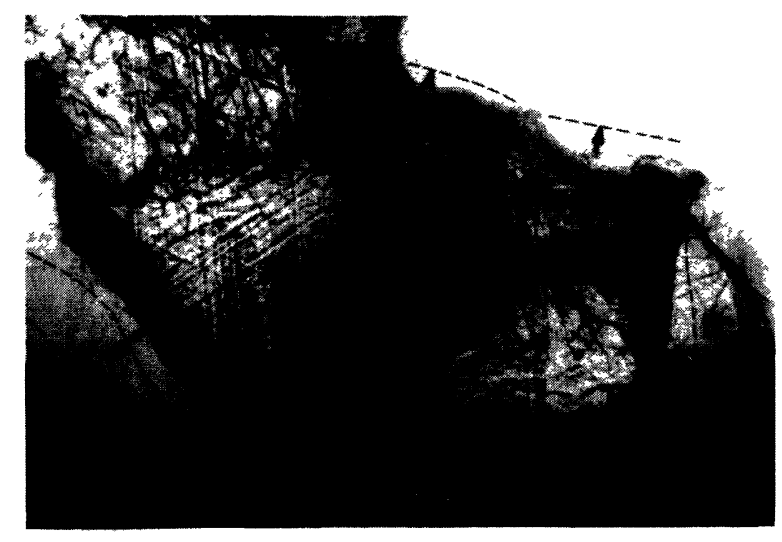

b)

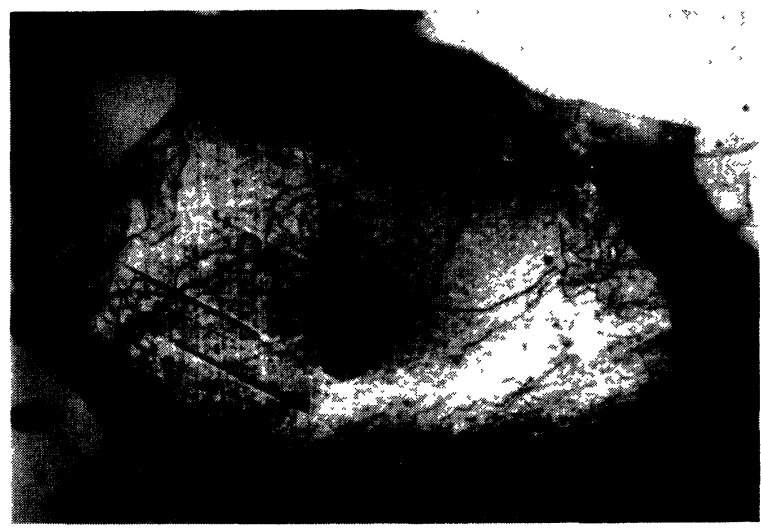

Fig. 12. - Subboundary migration during an in situ creep experiment. $1 \mathrm{MeV}, 200^{\circ} \mathrm{C}$. Aluminium. a) Initial state ; b) $1 \mathrm{~h}$ later, local additional strain $=12 \%$. Dotted lines in a) correspond to subboundaries in b). Subgrain $A$ is growing while B is shrinking. Subboundary formation in C. [26].

\begin{tabular}{|l|c|c|c|}
\hline & $T$ & $\varepsilon_{\mathrm{SB}} / \varepsilon_{\mathrm{T}}$ & Ref. \\
\hline $\mathrm{LiF}$ & $600^{\circ} \mathrm{C}$ & $100 \%$ & {$[41]$} \\
$\mathrm{LiF}$ & $500^{\circ} \mathrm{C}$ & 5 to $25 \%$ & {$[42]$} \\
$\mathrm{NaCl}$ & $680^{\circ} \mathrm{C}$ & $30 \%$ & {$[43]$} \\
$\mathrm{NaCl}$ & $600^{\circ} \mathrm{C}$ & & {$[44]$} \\
$\mathrm{Argon}$ & $77 \mathrm{~K}$ & 3 to $30 \%$ & {$[45]$} \\
$\mathrm{Al}$ & 20 to $200{ }^{\circ} \mathrm{C}$ & 3 to $25 \%$ & {$[16,26]$} \\
$\mathrm{Al}$ & 400 to $600{ }^{\circ} \mathrm{C}$ & $25 \%$ & {$[46]$} \\
$\mathrm{AlZn} 11 \mathrm{wt} \%$ & $250^{\circ} \mathrm{C}$ & 5 to $10 \%$ & {$[31]$} \\
\hline
\end{tabular}

Subboundary migration also plays an important role during recovery, and as a possible source of internal stress, as detailed below.

4.1 SUBBOUNDARY MIGRATION AND RECOVERY. - The misorientation of neighbouring subboundaries usually have large components of opposing sign. Therefore, they tend to move in opposite directions under stress, and to react or annihilate, leading to a decrease of the total dislocation density and an increase of the mean subgrain size as strain increases. This corresponds to a recovery process, as mentionned in $[5,26]$, and has been directly verified 
in [47], for aluminium. In a work of Blum [42], this mechanism is even considered important enough to account for the quasi stationnary stage of creep in LiF. Particularly, this explains why subgrain misorientation does not necessarily increase rapidly during deformation. Lastly, subboundary migration also plays an important role in the initiation of dynamic recrystallization in copper and nickel as evidenced by Kocks [48].

4.2 SUBBOUNDARY MIGRATION AND INTERNAL STRESSES. - It has been mentionned in $\S 2$ that subboundary migration could be the source of internal stresses either by subboundary bending or by incompatibilities of glide between extrinsic and intrinsic dislocations. It can be noticed that this hardening behaviour is consistent with the previous one and that both effects of subboundary migration certainly coexist during creep.

4.3 MEChANISM OF SUBbOUNDARY MIGRATION. An important question to be addressed is whether climb is required for the subboundary migration process.

In $\mathrm{LiF}$, at $500{ }^{\circ} \mathrm{C}$, and in copper and nickel at $0.4 T_{\mathrm{m}}$, subboundary migration is supposed to be controlled by the climb of some dislocation segments or debris [42, 49]. The authors in [42] consider that this process obeys the same rate equations as for the jogged screws. However, it is in fact quite different since the stress dependance is weak in the former case (dislocation climb), while it is stronger for jogged screws (the activation area is proportional to the distance between jogs) (cf. § 6).

Conversely in aluminium since the speed of migration is much larger than the speed of climb at $20^{\circ} \mathrm{C}$ $\left(0.3 T_{\mathrm{m}}\right)$, and since its stress dependence is also much larger than that expected for climb of some dislocation segments $(n \gg 1)$, we have concluded that subboundaries migrate by glide $[16,26]$. This is in agreement with the glissile geometry mentioned in $\S 3$. However, migration then requires glide of some screw segments on $\{100\}$ planes, probably by nucleation and propagation of single kinks. This process of glide in non-compact planes (more completely described in $\S 6$ ) is then certainly rate controlling for the speed of subboundary migration in Al between 0.2 and $0.5 T_{\mathrm{m}}$. The speed of migration can then be written [16] :

$$
V_{\text {migr }}=\nu_{\mathrm{d}}\left(b^{2} / h\right) \exp -\frac{\Delta G}{k T},
$$

with : $\quad \nu_{\mathrm{d}} \quad$ Debye frequency

$h$ subboundary mesh size

$\Delta G=U_{\mathrm{k}}+\tau b \Delta l-\sigma b A$

$U_{\mathrm{k}} \quad$ kink energy in $\{100\}$

$\tau \quad$ line tension

$\Delta l<b(\tau b \Delta l<\sigma b A)$

$A \quad$ activation area $\sim b h$.
However, climb may be involved in aluminium above $0.5 T_{\mathrm{m}}$, since subboundaries have a more complex geometry and may not be glissile (§ 3 ).

\section{Stress dependence of the strain rate and power law breakdown (PLB).}

The different values of the stress exponent $n$ which have been reviewed in $\S 1$ are not yet well explained, in the different temperature ranges. We present below different attempts to better understand the power law and the power law breakdown.

5.1 High TEMPERATURES (POWER LAW). - Classical models of recovery controlled creep give $n=3$ since the dislocation climb velocity is considered to be proportional to $\sigma$ and the dislocation density to $\sigma^{2}$. It is then necessary to make ad hoc hypotheses in order to increase $n$ up to 5. One way is to suppose that the internal stress increases more rapidly than the applied stress. For instance, the model of subboundary flexing under stress already described [24], (see $\S 2$ and 4.2) can explain $n=4$ to 7. These values are not high enough for the intermediate range in which subboundaries are more over not always present.

5.2 INTERMEDIATE TEMPERATURES (POWER LAW BREAKDOWN). - According to different authors, the power law breakdown may correspond to either a change of substructure and internal stresses, or a change of the controlling mechanism, or no change at all. These three hypotheses are detailed below.

5.2.1 The power law breakdown may correspond to a transition between a structure of subgrains limited by subboundaries, and a structure of cells limited by cell walls, according to [50], where it is supposed that subboundaries are destroyed under high stresses.

In fact, there may be a tendency to a more imperfect substructure at intermediate temperatures. For instance, in steel at high temperatures a subboundary substructure is observed and at intermediate temperatures a mixture of subboundaries and cell walls are present, according to [51]. However, there is probably no direct correlation between substructure change (and the corresponding internal stress change) and power law breakdown [22, 51], but more probably a common origin. Besides, subboundaries are present in aluminium at intermediate temperature, in the power law breakdown range [33]. This indicates that in this case climb is an active mechanism even in the power law breakdown regime.

5.2.2 The power law breakdown may also correspond to a change of the controlling creep mechanism (see $\S 6$ ), i.e. :

- transition from a recovery controlled mechan- 
ism towards a thermally activated glide controlled mechanism, such as forest cutting [52] or glide in non compact planes [16]. Then the largest stress dependence explains the PLB. Nix and Ilschner [3] believe that recovery and thermally activated glide should be localized in hard and soft zones respectively ;

- transition towards recovery which is controlled by alternative processes, such as pipe diffusion $[7,53,54]$ (however, $n$ only increases by 2 ) and cross slip [55].

5.2.3 On the other hand, some authors propose a single equation to express the creep rate for the whole temperature range. Then it is not necessary to hypothesize a change in the controlling mechanism to explain the power law breakdown. Rather, PLB could occur when the stress dependence of the exponential term becomes equivalent to the power law stress dependence of the pre-exponential factor. However, the interpretations of the single constitutive equation are in contradiction since it has been shown by $[10,56,57]$ that the controlling mechanism cannot be diffusion, while another investigation [8] claims that the mechanism should be the climb of jogs on screw dislocations (however between 0.5 and $0.9 T_{\mathrm{m}}$ only).

\section{The possible fundamental rate controlling mechanisms.}

Numerous mechanisms have been proposed, especially at intermediate temperatures. They can be separated into two different groups : those considering recovery and those based on thermally activated glide.

\subsection{RECOVERY CONTROLLED MECHANISMS.}

6.1.1 Self diffusion controlled climb of edges (high temperatures) [3, 7, 42, 53, 54]. - Based solely on the values of the activation energy which have been measured, edge dislocation climb through self diffusion is considered to control creep at high temperatures. According to the authors, this process can be active in different ways. Nix and Ilschner [3] claim that recovery takes place in the hard zones (subboundaries) under stresses larger than the applied stress. On the contrary, it has also been postulated that the dislocation density decreases because of climb induced annihilation in the soft zones. This allows new sources to be activated [27].

6.1.2 Pipe diffusion controlled climb of edges (intermediate temperatures). - Because of a fairly good agreement between the activation energy of the intermediate temperature plateau (see $\S 1$ ) and the presumed activation energy for pipe diffusion, several authors claim $[7,53,54]$ that the creep rate could be controlled by recovery occurring through pipe diffusion. The model derivation is roughly the same as for high temperatures, except that diffusion along dislocation cores takes over.

6.1.3 Cross slip of screw dislocations. - This mechanism has also been considered, although little is known about cross slip in general. It certainly represents another recovery process, complementary to those mentioned previously, acting on screw dislocations [55]. For instance, cross slip has been proposed to explain the ultra high temperature domains in semiconductors [58] and HCP metals [59]. A model has also been developed by Friedel [60] in which the rate controlling process is the escaping of dislocations from subboundaries by cross-slip, following the experimental observations of Caillard and Martin [5]. The critical stress for cross slip, as well as its stress dependence on temperature and strain rate, was estimated from the values of $\tau_{\text {III, }}$ which corresponds to the onset of stage III on the stress strain curves. However, this is an indirect method and is not accurate enough to provide values from which the correct creep and deformation laws can be derived.

Very recent results on the activation parameters of cross slip have shed some light on this controversy. A new method has been developed to study this process and has been applied to copper [28,61]. An avalanche of cross slip events is produced at the elastic limit, after an appropriate predeformation. True activation volumes are measured at the elastic limit by stress relaxation experiments. Cross slip is observed between 250 and $407 \mathrm{~K}$, with an activation volume of about $350 b^{3}$ independent of stress and temperature. This value is in excellent agreement with the predictions of Escaig's model of cross slip [62] and the dislocation width of splitting which were formerly measured in copper [63]. The activation energy values, which at the moment have been derived from the volumes, are $\Delta G_{0}=1.15 \pm$ $0.37 \mathrm{eV}$ [28], also in reasonable agreement with the model. The validity of Escaig's model for cross slip has also been confirmed by the asymmetry of the yield stress in tension and compression [61].

The values of $\Delta G_{0}$ for cross slip are compatible with experimental values of the creep activation energy for copper at intermediate temperatures (about $1.45 \mathrm{eV}$, see Fig. 1c). For other crystals, similar cross slip data are not available at the moment.

6.2 Thermally ACtivated Glide. - Generally, all these models well account for the stress dependence of the strain rate at intermediate temperatures (see § 1 ) and can explain the occurrence of the power law breakdown, by introducing an activation area $A$ of a few hundred $b^{2}$.

6.2.1 Glide of jogged screw dislocations $[8,39,42$, 58]. - This model is still widely considered because 
it is the only diffusion controlled model which can well explain both high temperature creep, with the activation energy of self diffusion, and the power law breakdown at intermediate temperature, by introducing an activation area.

The corresponding velocity of dislocations is

$$
v=v_{0} \exp -\left(\frac{\Delta G_{0}-\sigma b A}{k T}\right)
$$

with $\Delta G_{0}=$ self diffusion energy at high temperature, and possibly energy for pipe diffusion at lower temperatures, $A \sim$ a few $100 b^{2}$ (i.e. jog spacing $\simeq 100 \mathrm{~b}$ ).

Then the corresponding creep law is :

$$
\dot{\varepsilon}=C \sigma^{n} \exp -\left(\frac{\Delta G_{0}-\sigma b A}{k T}\right)
$$

with $n=3$ to 6 , according to the models, $C$ being a constant.

This mechanism is quoted by the following authors :

Blum [30] considers that jogs are formed during subboundary cutting by mobile screws. The experimentally observed proportionality between the subboundary mesh size and $A$ can then be explained.

Another type of model [42] proposes that creep is controlled by subboundary migration, which is itself limited by a mechanism equivalent to the climb of jogged screws. This model has been criticized in $\S 4$.

For other authors $[8,58]$, the creep rate and the stress corresponding to the onset of stage III in FCC metals above $0.5 T_{\mathrm{m}}$ are governed by this process.

6.2.2 The forest mechanism. - This mechanism may operate in the soft zones according to [3]. On the other hand, it has also been proposed that the obstacles are the attractive trees in the hard zones $[22,56,64]$. A thermally activated unzipping mechanism has been developed for stage III [64]. However, the unreasonable assumption is made that junction reactions of about $3 b$ in length could have widths of splitting of the order of $10 \mathrm{~b}$. The obstacles have also been considered to be the repulsive trees in the subboundaries $[23,36,52]$. The activation energy corresponds to that for a jog pair formation and has a value of a few tenths of an $\mathrm{eV}$, which is a bit weak as compared to those measured in creep.

6.2.3 Glide on non compact planes. - Glide on non compact planes is known to operate in the HCP and the FCC structures and some data are now available on this process. The HCP metals have been observed to glide on the prism plane in macroscopic experiments (see, for instance, [65] for magnesium). For these metals, the creep activation energy as a function of temperature has been measured (Fig. 1b). High activation energies at ultra high temperatures have been interpreted usually in terms of cross slip of dislocations from the basal plane onto the prism plane. At lower temperatures, between about 0.4 and $0.7 T_{\mathrm{m}}$, the creep activation energy becomes comparable to that of self diffusion [6] and dislocation climb is considered to be the rate controlling process. However, a detailed study of prismatic glide in $\mathrm{Mg}$ has been performed recently by in situ TEM observations of dislocation motion in [66]. Straight screw dislocations were observed to move slower than edge portions. An analysis of the screw velocities as a function of stress and temperature agrees with Escaig's theory [67].

The screw dislocation velocity in the prism plane is :

$$
V=\sqrt{(2 / 3)} \nu_{\mathrm{d}} \frac{b^{2}}{l_{\mathrm{c}}^{2}} L \exp -\frac{\Delta G_{\mathrm{k}}-\sigma b A}{k T}
$$

with $\nu_{\mathrm{d}}$ : Debye Frequency

$l_{\mathrm{c}} \quad$ : critical length for nucleating a kink pair $\left(l_{\mathrm{c}} \sim A / b\right)$

$L \quad$ : dislocation length

$\Delta G_{\mathrm{k}} \quad$ : energy of a kink pair in the non compact plane

$A$ : activation area (a few $10 b^{2}$ to a few $100 b^{2}$.

The proportionality between $V$ and $L$ (length effect) has been verified directly. The activation energy found at $600 \mathrm{~K}$ agrees reasonably well with those measured in creep in the so called «self diffusion " temperature range.

Therefore, it is not unreasonable to suppose that glide on the prism plane controls the creep rate of some hexagonal metals between about 0.4 and $0.7 T_{\mathrm{m}}$, and that cross slip is not rate controlling at ultra high temperatures.

Similar results are obtained in FCC crystals. Glide on (001) has been studied in [112] single crystals of aluminium [15]. These exhibit a high Schmid factor on the $1 / 2[110](001)$ system. Constant strain rate experiments produce slip traces on (001) at temperatures higher than about $270^{\circ} \mathrm{C}$ (for $\dot{\gamma} \sim 10^{-4} \mathrm{~s}^{-1}$ ) $[14,15]$. The critical stress for glide on (001) was measured as a function of temperature and strain rate. The activation energy was found to be $\Delta G_{0} \simeq 1.34 \mathrm{eV}$, which can also be understood in terms of the kink pair mechanism. This result is also consistent with the observations of long screw dislocations in pinned dislocation arrangements using $\mathrm{AlZn}$ or in situ experiments [15]. Under creep conditions, metallographic observations reveal (001) glide at temperatures above $180^{\circ} \mathrm{C}$. Therefore, in aluminium, there is a good agreement between the activation energies for (001) glide and creep, respectively. These results suggest that (001) glide is rate controlling at these temperatures $\left(T>180{ }^{\circ} \mathrm{C}\right)$. In addition, for creep of aluminium at intermediate temperatures, a model based on (001) glide has been developed recently [16]. 
It postulates that the creep rate may be proportional to the frequency with which dislocations are extracted from the subboundaries. In this interpretation, the high local internal stress values which are necessary for dislocation extraction originate from the glide incompatibilities of the subboundary dislocations during migration. The emission frequency of dislocations out of subboundaries is proportional to the migration velocity which consequently controls creep so that $\dot{\varepsilon} \alpha v_{\text {migr. }}$. Finally, the migration velocity is itself controlled by the slip rate of those dislocation segments which lie on non compact planes (see $\S 4.3$ ). A stress exponent close to 5 is obtained for the pre-exponential term, the activation energy is smaller than that for self diffusion, and the activation area is of the order of $100 b^{2}$, in agreement with macroscopic data (see Fig. 3).

\section{Discussion.}

This tentative description of the «state of the art » seems to indicate that our concept of creep has been changing over the ten last years. The models used to ignore the substructure observations. Moreover, they did not describe correctly obvious macroscopic observations such as power laws with correct $n$ values, power law breakdown and activation parameters when they were different from those of selfdiffusion. In contrast, more recent investigations provide new approaches to the creep mechanisms. In particular, the observation of a heterogeneous substructure has led to the concept of a heterogeneous distribution of local stresses. Likewise, three dimensional pictures of dislocation subboundary interactions are more commonly used and yield a different view on the processes of crossing and annihilation at subboundaries. Subboundary migration during creep of a variety of materials is now accepted as a significant process, which should be included in any realistic creep model.

The various models can be classified according to which one of the three necessary elementary processes of creep is considered : dislocation emission, annihilation or transport between sources and sinks. Indeed, any one of these three processes may be rate controlling. In particular several new models of creep at intermediate temperatures postulate that the strain rate is controlled by the thermally activated glide of dislocations. They consider a constant activation area, rather than a varying stress exponent. Among these models, the jog dragging screw mechanism, although still very popular, appears to be particularly unrealistic. Indeed, if the moving jogged screw is considered, different situations can occur. Generally, dislocations are not perfectly straight. Thus, the jogs can move sideways by glide and therefore their motion no longer controls the mobility dislocation. Even if the screw dislocation is straight on average, it will bow out between jogs as sketched in figure 13 . In this case, it is easy to show that the configuration is unstable. In fact, the work done by the stress on the various dislocation segments is such that long segments will expand at the expense of short segments which will shrink by glide of the jogs. Jogs can then annihilate or form superjogs, the climb rate of which is completely different from isolated jogs. In this respect, the situation is very different from that of a screw gliding at low temperature in a BCC metal or in a non compact plane in HCP or FCC structures. In the latter case, the screw remains straight when the kink mobility is large and kink nucleation is a difficult process. It is also interesting to note that one of the authors of the jogged screw model no longer supports it on the basis of the analysis of strain transients [3].

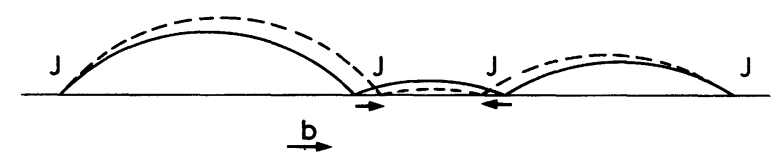

Fig. 13. - Sketch of jogged screw dislocation glide. Two successive positions. $J=$ jog (see text).

Cross slip is also a frequently quoted mechanism. We have shown that it is now possible to have direct access to the corresponding activation parameters which are different from those derived from the $\tau_{\text {III }}$ considerations. If other crystals besides copper are investigated, it will then be possible to decide under which conditions this mechanism is rate controlling.

Finally, a particular deformation mechanism of compact structures (FCC, HCP) which has been known to exist for a long time, namely glide on non compact planes, has been recently studied extensively, understood better and its connection to the creep rate established more clearly. For magnesium and aluminium, this type of glide can be described by a kink mechanism, the characteristics of which have been determined experimentally. However, the connection between this mechanism and the creep rate should be further studied. FCC metals different from aluminium should be investigated. In aluminium it should be confirmed that intermediate temperature creep is controlled by (001) glide during subboundary migration and high temperature creep by dislocation glide on non compact planes inside subgrains. The creep activation energy at zero stress would be that for one or two kinks respectively. The values of $U_{\mathrm{k}}$ estimated this far are of the order of $0.7 \mathrm{eV}$ in aluminium $[15,16]$ and the agreement with the creep activation energy is satisfactory in both temperature domains. This does not exclude the possibility that there exists a temperature domain 
closer to the melting point in which dislocation climb dominates. A similar interpretation of the magnesium creep rate could be attempted. It is clear that these new models of glide on non compact planes are a direct challenge to the rather unrealistic model of glide of jogged screws (at least in aluminium), since they have similar predicted values of activation parameters and they concern the same types of dislocations.

To conclude, the improvement of our knowledge of creep should take into account the following observations.

In spite of the large number of studies on specific materials, a large scatter exists in the data, especially for the activation energies in different temperatures ranges. To have a better insight into these different domains, it is recommended that creep tests be practiced over a wide range of stress and temperature values. The data should be plotted using three coordinate axes, such as $\log \dot{\varepsilon}, \sigma$, and $1 / T$ for instance (see an attempt in [55]). Unfortunately, the most popular method consists in exploring only planar sections of that space ( $T=$ Cst. or $\sigma=$ Cst.).

In many cases, another striking feature of the continuing arguments concerning the mechanisms responsible for the experimentally determined constitutive equations, is the lack of metallographic and microstructural information. For the most part, only the values of the activation energy or area are considered and compared to those related to given phenomena (self diffusion, etc...). This attitude can be misleading, as shown above. Useful metallographic informations can be gained from in situ observations of dislocation motion. In such experiments, the advantages of conventional electron microscopy are combined with those of macroscopic plastic deformation. Quantitative measurements can be obtained related to mobile dislocation densities, velocities, local stresses, etc., provided the possible artefacts inherent in the experiments are understood.
Another rewarding approach consists of comparing creep data to constant strain rate test data $[14,15]$. In the latter type of experiments, the dependence of the elastic limit on temperature indicates temperature and stress domains for which a given mechanism is operative. In addition, sophisticated techniques such as load relaxation experiments, or successive load relaxations, provide useful information about the stress sensitivity of the mechanism in question [28]. On the other hand, dip tests in creep, although currently very popular, seem to have been interpreted satisfactorily only in the case of alloy type materials [68]. Unfortunately, there exists a continuing controversy about the interpretation of such tests in the case of metal type behaviour $[20,69]$. Further developments are required for load relaxation experiments in creep tests [70]. In addition, load relaxation experiments in constant strain rate tests, at homologous temperatures higher than those currently used, should be conducted. The corresponding models accounting for the relaxation rate should also be adapted to high temperatures. However, as was mentioned in $\S 1$, although the same mechanisms may control the deformation rate in constant strain rate and creep tests, the temperature domains in which they occur may be quite different. The sample responds differently in these two distinct test conditions perhaps due to the fact that in creep it undergoes a continuous range of strain rates.

\section{Acknowledgments.}

The authors are grateful to Drs. Carrard, Couret and Bonneville for several discussions. They are indebted to Dr. Mills for fruitful comments on the manuscript. One of us (JLM) would like to thank Fonds National Suisse for supporting part of this study.
[1] Poirier, J. P., Creep of crystals (Cambridge University Press, Cambridge) 1985.

[2] Takeuchi, S., Argon, A. S., J. Mat. Sci. 11 (1976) 1542.

[3] NiX, W. D., ILSChNer, B., Strength of Metals and Alloys, Ed. P. Haasen, V. Gerold, G. Kostorz (Pergamon, Toronto) 3, 1980, p. 1503.

[4] Orlova, A., CadeK, J., Mat. Sci. Eng. 77 (1986) 1.

[5] Caillard, D., Martin, J. L., Acta Met. 31 (1983) 813.

[6] PoIrier, J. P., Plasticité à haute température des solides cristallins (Eyrolles, Paris) 1976, p. 52.

[7] Luthy, H., Miller, A. K., Sherby, O. D., Acta Met. 28 (1980) 169.
[8] Siethoff, H., Schröter, W., Ahlborn, K., Acta Met. 33 (1985) 443.

[9] Poirier, J. P., Acta Met. 26 (1978) 629.

[10] Mecking, H., Styczynski, A., Estrin, Y., Creep and Fracture of Engineering Materials and Structures, Ed. B. Wilshire and D. R. J. Owen (Pineridge Press, Swansea U.K.) 1, 1984, p. 115.

[11] Blum, W., RePpich, B., Acta Met. 17 (1969) 959.

[12] Wuh, M. Y. and Sherby, O. D., Acta Met. 32 (1984) 1561.

[13] Harper, J. and Dorn, J. E., Acta Met. 5 (1957) 654.

[14] Carrard, M. and MARTIN, J. L., Strength of Metals and Alloys, Ed. H. McQueen, J. Bailon, J. Dickson, J. Jonas and M. Akben (Pergamon, Toronto) 1, 1987, p. 665. 
[15] Carrard, M., Doctorate Thesis No. 595, Lausanne (1985). To appear in Philos. Mag. (1987).

[16] Caillard, D., Philos. Mag. A 51 (1985) 157.

[17] Mughrabi, H., Acta Met. 31 (1983) 1367.

[18] Morris, M. A., Martin, J. L., a) Acta Met. 32 (1984) 549 ;

b) Acta Met. 32 (1984) 1609.

[19] Caillard, D., Mat. Sci. Eng. 81 (1986) 349.

[20] Blum, W., Schmidt, H., Res. Mech. 9 (1983) 105.

[21] Blum, W., Scripta Met. 16 (1982) 1353.

[22] Kocks, U. F., Proc. 50th anniversary meeting on Dislocations and Properties of Real Materials (The Metal Society, London) 1984, p. 125.

[23] Myshlyaev, M. M., ICSMA 4 Edit. ENSMIM, Nancy, 3, 1976, p. 1037.

[24] Argon, A. S., Takeuchi, S., Acta Met. 29 (1981) 1877.

[25] Gibeling, J. C., NiX, W. D., Acta Met. 28 (1980) 1743.

[26] Caillard, D., Martin, J. L., Acta Met. 30 (1982) 791.

[27] Parker, J. D., Wilshire, B., Philos. Mag. A 41 (1980) 665.

[28] Bonneville, J., Doctorate Thesis No. 607, Lausanne (1985). To be published in Acta Met.

[29] Tabata, T., Fujita, H., Hiraoka, M., Miyake, S., Philos. Mag. A 46 (1982) 801.

[30] Caillard, D., Acta Met. 32 (1984) 1483.

[31] Morris, M., Masson, D., Senior, B., Martin, J. L., Scripta Met. 17 (1983) 687.

[32] CAillaRD, D. and MARTin, J. L., The structure and properties of crystal defects, Ed. V. Paidar and J. Lejcek (Elsevier, Amsterdam) 1984, p. 447.

[33] Caillard, D., Martin, J. L., Acta Met. 30 (1982) 437.

[34] Brion, H. and HaAsen, P., Philos. Mag. A 51 (1985) 879.

Brion, H., HAASEN, P. and SiEThoff, H., Strength of Metals and Alloys, Ibidene, 1 (1987) 15.

[35] Lindroos, V. K. and Miekk-Oja, H. M., Philos. Mag. 16 (1967) 593.

[36] Myshlyaev, M. M., Ann. Rev. Mater. Sci., Ed. R. A. Huggins, R. H. Bube, D. A. Vermilyea, Palo Alto, California, Vol. 11 (1981) p. 31.

[37] Hakkainen, T. J., Lindroos, V. K., Scripta Met. 17 (1983) 1459.

[38] Weertman, J., Trans. A.S.M. 61 (1968) 681.

[39] Blum, W., Z. Metallkunde 68 (1977) 484.

[40] Blum, W., Münch, H., Portella, P. D., Creep and Fracture of Engineering Materials and Structures, Ed. B. Wilshire and D. R. J. Owen (Pineridge Press, Swansea U.K.), 1, 1984, p. 131.

[41] Smirnov, B. I., Speizman, V. V., Privalova, T. V., Samoilova, T. V., Sov. Phys. Solid State 18 (1976) 1419.
[42] Vollertsen, F., Hofbeck, R., Blum, W., Mater. Sci. Eng. 67 (1984) L9.

[43] Pontikis, V., Thèse d'Etat, Université Paris VI (1977).

[44] Fries, E., Deschamps, J., Castaing, J., Rad. Eff. 74 (1983) 329.

[45] Leontéva, A. V., Romanusha, V. A., Feldman, E. P., Sov. Phys. Sol. State 24 (1982) 674.

[46] Exell, S. F., Wạrington, D. H., Philos. Mag. 26 (1972) 1121.

[47] Hasegawa, T., Kocks, U. F., Acta Met. 27 (1979) 1705.

[48] Cook, R. E., GotTstein, G., Kocks, U. F., J. Mat. Sci. 18 (1983) 2650.

[49] Prinz, F., Argon, A. S., Moffatt, W. C., Acta Met. 30 (1982) 821.

[50] Pharr, G. M., Scripta Met. 15 (1981) 713.

[51] KASSNER, M. E., Materials Lett. 2 (1984) 451.

[52] Arieli, A., Mukerjee, A. K., Creep and Fracture of Engineering Materials and Structures, Ed. B. Wilshire and D. J. Owen (Pineridge Press, Swansea U.K.) 1981, p. 97.

[53] Sherby, O. D., Miller, A. K., J. Eng. Mat. Techn. 101 (1979) 387.

[54] Evans, H. E., Knowles, G., Acta Met. 25 (1977) 963.

[55] Poirier, J. P., Revue Phys. Appl. 11 (1976) 731.

[56] Nicklas, B., MECKING, H., Strength of Metals and Alloys, ibidem 1 (1979) 351.

[57] Mecking, H., Nicklas, B., Zarubova, N., KocKs, U. F., Acta Met. 34 (1986) 527.

[58] Siethoff, H., SCHRÖter, W., Z. Metallkunde 75 (1984) 475 and 482.

[59] Vagarali, S. S. and Langdon, T. G., Acta Met. 29 (1981) 1969.

[60] Friedel, J., Rev. Phys. Appl. 12 (1977) 1649.

[61] Bonneville, J. and Escaig, B., Acta Met. 27 (1979) 1477.

[62] Escaig, B., J. Physique 29 (1968) 225.

[63] Stobis, W. M. and Sworn, C. H., Philos. Mag. 24 (1971) 1365

[64] Sastry, D. H., Luton, M. J., Jonas, J. J., Philos. Mag. 30 (1974) 115.

[65] Ahmadieh, A., Mitchell, J., Dorn, J. E., Trans. Met. Soc. AIME 233 (1965) 1130.

[66] Couret, A. and Caillard, D. Acta Met. 33 (1985) 1447 and 1455.

[67] Escaig, B., Phys. Status Solidi 28 (1968) 463.

[68] Mills, M. J., Gibeling, J. C. and NiX, W. D., Acta Met. 33 (1985) 1503.

[69] Gibeling, J. C. and NIX, W. D., 29 (1981) 1769.

[70] Osthoff, W., Schuster, H., EnNis, P. J. and NICKEL, H., Creep and Fracture of Engineering Materials and Structure, Vol. 1, B. Wilshire and D. R. J. Owen, Edit. (Pinebridge Press, Swansea) 1984 , p. 307. 